\title{
Effects of neuromuscular blocking agents on central respiratory chemosensitivity in newborn rats
}

\author{
SHIGEKI SAKURABA ${ }^{1,2 *}$, SHUN-ICHI KUWANA ${ }^{3}$, LARS I. ERIKSSON ${ }^{2}$, \\ YASUMASA OKADA ${ }^{4}$, RYOICHI OCHIAI ${ }^{1}$, MASANORI KASHIWAGI $^{1}$, \\ EIKI HATORI ${ }^{1}$, STEN G. E. LINDAHL ${ }^{2}$ and JUNZO TAKEDA ${ }^{1}$
}

\footnotetext{
${ }^{1}$ Department of Anesthesiology, School of Medicine, Keio University, 35 Shinanomachi, Shinjuku-ku, Tokyo 160-8582, Japan.

2 Department of Anesthesiology and Intensive Care, Karolinska University Hospital and Institute, SE-171 76 Stockholm, Sweden

${ }^{3}$ Department of Physiology, School of Medicine, Teikyo University, 2-11-1 Kaga, Itabashi-ku, Tokyo 1738605 , Japan.

${ }^{4}$ Department of Medicine, Keio University Tsukigase Rehabilitation Center, 380-2 Amagiyugashima-cho, Tagata-gun, Shizuoka 410-3293, Japan.
}

\begin{abstract}
Neuromuscular blocking agents suppress central respiratory activity through their inhibitory effects on preinspiratory neurons and the synaptic drive from preinspiratory neurons to inspiratory neurons. Central $\mathrm{CO}_{2}$-chemosensitive areas, which partly consist of $\mathrm{CO}_{2}$-excited neurons, in the rostral ventrolateral medulla are thought to provide tonic drive to the central respiratory network and involve cholinergic mechanisms, which led us to hypothesize that neuromuscular blocking agents can inhibit $\mathrm{CO}_{2}$-excited neurons and attenuate respiratory $\mathrm{CO}_{2}$ responsiveness. To test this hypothesis, we used isolated brainstem-spinal cord preparations from newborn rats. The increase of $\mathrm{C} 4$ burst frequency induced by a hypercapnic superfusate, i.e. respiratory $\mathrm{CO}_{2}$ responsiveness, was suppressed by the application of neuromuscular blocking agents, either d-tubocurarine $(10,100 \mu \mathrm{M})$ or vecuronium $(100 \mu \mathrm{M})$. These agents $(40 \mu \mathrm{M})$ also induced hyperpolarization and decreases in firing frequency of $\mathrm{CO}_{2}$-excited neurons in the rostral ventrolateral medulla. Our results demonstrate that neuromuscular blocking agents inhibit $\mathrm{CO}_{2}$-excited tonic firing neurons and attenuate respiratory $\mathrm{CO}_{2}$ responsiveness.
\end{abstract}

Key terms: brainstem, chemosensitivity, $\mathrm{CO}_{2}$ responsiveness, muscle relaxant, nicotinic acetylcholine receptor

\section{INTRODUCTION}

Central $\mathrm{CO}_{2}$ chemosensitivity plays a crucial role in central respiratory control. Chemosensitive neurons, i.e. $\mathrm{CO}_{2}$-excited neurons, in the rostral ventrolateral medulla (RVLM) are thought to provide tonic drive to the neuronal network that generates the respiratory rhythm (Eugenin \& Nicholls, 1997; Richerson, 1998; for review, see Eugenin et al., 2001) partly by cholinergic mechanisms (for review, see Loeschcke, 1982; Eugenin \& Nicholls, 1997; Eugenin et al., 2001; Okada et al., 2001). A clear relationship between endogenous cholinergic mechanisms and central chemoreception has been found using the isolated brainstemspinal cord preparation of neonatal rat (Monteau et al., 1990) and of opossum (Eugenin \& Nicholls, 1997). In these preparations, the increase in respiration induced by acetylcholine (ACh) and acetylcholinesterase inhibitors show a similar pattern as that induced by low $\mathrm{pH}$ stimulation (Monteau et al., 1990; Eugenin \& Nicholls, 1997). ACh- and low pH-

\footnotetext{
* Corresponding author: Dr. Shigeki Sakuraba, Department of Anesthesiology, School of Medicine, Keio University, 35 Shinanomachi, Shinjuku-ku, Tokyo 160-8582, Japan. Tel.: (81-3) 3353-1211, ext. 62492, Fax: (81-3) 3356-8439, E-mail: Shigeki.Sakuraba@kirurgi.ki.se
} 
sensitive areas in the RVLM overlapped (Eugenin \& Nicholls, 1997).

The cholinergic nature of chemosensitive neurons in the RVLM has been investigated extensively. Chemosensitive neurons sensitive to $\mathrm{H}^{+}$are excited by $\mathrm{ACh}$ and depressed by muscarinic and nicotinic cholinergic blocking agents in the medulla slice preparation of rat (Fukuda \& Loeschcke, 1979; for review, see Okada et al., 2001). The application of atropine attenuates respiratory $\mathrm{CO}_{2}$ responsiveness in the in vivo anesthetized cat (Dev \& Loeschcke, 1979) and in the in vitro preparation of neonatal rat (Monteau et al., 1990). The topical application of nicotine on chemosensitive areas in the RVLM induces hyperventilation, and intravenous injection of hexamethonium, a nicotinic ACh receptor (nAChR) antagonist, diminishes nicotineinduced hyperventilation in the in vivo anesthetized rat (Dev \& Loeschcke, 1979). More interestingly, muscarine reverses the opioid-induced suppression of respiratory (C4) activity in parallel with chemosensitive $\mathrm{CO}_{2}$-excited neuron activity in the isolated brainstem-spinal cord preparation of neonatal rat (Ballanyi et al., 1999), indicating the direct relationship between chemosensitive $\mathrm{CO}_{2}$-excited neurons in the RVLM and the efferent respiratory activity.

Respiratory $\mathrm{CO}_{2}$ responsiveness is partly inhibited by the non-selective nAChR antagonist mecamylamine and a $4 \mathrm{~b} 2 \mathrm{nAChR}$ selective antagonist dihydro-b-erythroidine in the isolated brainstem-spinal cord preparation of neonatal rat (Kuwana et al., $2000 a, b)$. This result indicates that the $a 4 b 2$ nAChR subunit plays a role in central chemosensitivity as above. In a recent study, atracurium, one of the neuromuscular blocking agents (NMBAs), blocks a 4b2 nAChRs expressed in Xenopus oocytes (Chiodini et al., 2001), although the subunit composites of neuronal and muscle nAChRs vary (Lindstrom et al., 1995). Furthermore, our previous study has revealed that NMBAs suppress central respiratory control by their inhibitory effects on preinspiratory neurons and on the excitatory connection from preinspiratory neurons to inspiratory neurons (Sakuraba et al., 2003). Taken together, it is possible that NMBAs suppress central chemosensitivity by blocking excitatory input to central respiratory control (Eugenin \& Nicholls, 1997; Richerson, 1998; for review, see Eugenin et al., 2001), via a4b2 nAChR in the RVLM. Therefore, we hypothesized that NMBAs suppress respiratory $\mathrm{CO}_{2}$ responsiveness by their inhibitory effects on chemosensitive $\mathrm{CO}_{2}-$ excited neurons of the RVLM.

The purpose of this study is to investigate the effect of NMBAs on respiratory $\mathrm{CO}_{2}$ responsiveness and chemosensitive $\mathrm{CO}_{2}$-excited neurons in the RVLM.

\section{MATERIALS AND METHODS}

\section{Isolated brainstem-spinal cord preparation}

All experiments were approved by the Animal Experimentation Ethics Committee of the Keio University, Tokyo, Japan. Data were obtained from 86 neonatal Wistar rats (1-4 days old) using the isolated brainstemspinal cord preparation as previously described in detail elsewhere (Kuwana et al., 1998; Sakuraba et al., 2003). In brief, the brainstem with the cervical spinal cord was isolated under deep ether anesthesia. The cerebellum and pons were ablated in a chamber filled with oxygenated, artificial cerebrospinal fluid (ACSF) consisting of (in $\mathrm{mM}) 126 \mathrm{NaCl}, 5 \mathrm{KCl}, 1.25 \mathrm{NaH}_{2} \mathrm{PO}_{4}, 2$ $\mathrm{CaCl}_{2}, 2 \mathrm{MgSO}_{4}, 26 \mathrm{NaHCO}_{3}$ and 30 glucose. Then, the preparation was transferred to a recording chamber of $2 \mathrm{ml}$ volume and was fixed with miniature pins on a silicon rubber base with the ventral side up. The preparation was superfused at $26^{\circ} \mathrm{C}$ with control ACSF $\left(2 \% \mathrm{CO}_{2}\right.$ in $\mathrm{O}_{2}$; $\mathrm{pH}=7.8)$. With such alkaline ACSF, tissue $\mathrm{pH}$ of the superficial $(<400 \mu \mathrm{m})$ medullary layer could be maintained in the physiological range (Okada et al., 1993a). The activity of $\mathrm{C} 4$ ventral roots was recorded using a glass suction electrode, amplified with a conventional AC amplifier (AVH 11, Nihon Kohden, Tokyo, Japan) and integrated (time constant $100 \mathrm{msec}$ ). The signals were recorded on a thermal array recorder and stored on digital tape for 
subsequent analysis. The C4 burst frequency was measured as the respiratory frequency $\left(f_{\mathrm{R}}\right)$. The $\mathrm{pH}$ of the superfusate was continuously monitored with a conventional glass $\mathrm{pH}$ electrode calibrated using two different calibration solutions with known $\mathrm{pH}$ values. The control ACSF was replaced by several ACSF solutions in accordance with the protocol.

\section{Neuronal recording}

Activities of tonic firing neurons in the superficial (<400 $\mu \mathrm{m}$ ) RVLM were recorded intracellularly using a blind patch clamp configuration (Kuwana et al., 1998; Sakuraba et al., 2003). Briefly, a glass pipette (GC100TF-10, Clark Electromed, Reading, UK) was pulled with a horizontal puller (PA-91, Narishige, Tokyo, Japan) to a tip size of approximately $2 \mu \mathrm{m}$. Electrode resistance ranged from 12 to $16 \mathrm{M} \Omega$ when it was filled with a solution containing (in nM) $130 \mathrm{~K}$-gluconate, 10 EGTA, 10 HEPES, $1 \mathrm{CaCl}_{2}, 1 \mathrm{MgCl}_{2}$, and nystatin $(100 \mu \mathrm{g} / \mathrm{ml}) ; \mathrm{pH}$ was adjusted to $7.2-7.3$ by using $\mathrm{KOH}$. The micropipette was inserted into the RVLM with a manual hydraulic micromanipulator. Membrane potentials were recorded with a whole cell patch amplifier (CEZ 3100, Nihon Kohden, Tokyo, Japan). Neurons were searched for by applying positive pressure $(10-20 \mathrm{~cm}$ $\mathrm{H}_{2} \mathrm{O}$ ) inside the pipette. After giga-ohm seal was obtained, the recorded membrane potential became gradually negative and was stabilized in about $10 \mathrm{~min}$. The membrane potential $\left(\mathrm{E}_{\mathrm{m}}\right)$ was presented without correcting the liquid junction potential. The firing frequency was also calculated as the number of spikes per second. This perforated patch recording remained stable for more than $60 \mathrm{~min}$.

\section{Protocols}

After the preparation was superfused with control ACSF $\left(2 \% \mathrm{CO}_{2}\right.$ in $\left.\mathrm{O}_{2} ; \mathrm{pH}=7.8\right)$ for more than $30 \mathrm{~min}$ and the stable recording of the $\mathrm{C} 4$ activities was established, experiments were conducted using the following protocol.
Protocol-1: Neuromuscular blocking agent and respiratory $\mathrm{CO}_{2}$ responsiveness

Respiratory $\mathrm{CO}_{2}$ responsiveness was tested first without NMBA by switching superfusate from control ACSF to high $\mathrm{CO}_{2}$ /low pH ACSF $\left(8 \% \mathrm{CO}_{2}\right.$ in $\mathrm{O}_{2} ; \mathrm{pH}=$ 7.2) (7 $\mathrm{min})$, followed by a washout period using control ACSF again for more than 10 min. Then, respiratory $\mathrm{CO}_{2}$ responsiveness was tested by superfusion with dtubocurarine (D-TC; Sigma, St. Louis, MO, USA) $(1,10,100 \mu \mathrm{M})$ or vecuronium bromide (VB; Organon, Amsterdam, the Netherlands) $(10,100 \mu \mathrm{M})$. Respiratory $\mathrm{CO}_{2}$ responsiveness was defined as the difference of $f_{\mathrm{R}}$ between $2 \% \mathrm{CO}_{2}(\mathrm{pH}=$ $7.8)$ and $8 \% \mathrm{CO}_{2}(\mathrm{pH}=7.2)\left(\mathrm{D} f_{\mathrm{R}}\right)$. Preparations in which respiratory activity was completely abolished by NMBA or complete recovery was not obtained were excluded from the study.

Protocol-2: Neuromuscular blocking agent and the activity of tonic firing neurons in the rostral ventrolateral medulla

Control ACSF was changed to high $\mathrm{CO}_{2} /$ low $\mathrm{pH}$ ACSF $\left(8 \% \mathrm{CO}_{2}\right.$ in $\left.\mathrm{O}_{2} ; \mathrm{pH}=7.2\right)$ and then intracellular recording of chemosensitive neurons by blind patch clamp techniques was tried because the firing of chemosensitive neurons was increased by hypercapnic superfusate (Kawai et al., 1996), which made the search for chemosensitive neurons easier. After this was performed, the preparation was superfused by high $\mathrm{CO}_{2} /$ low $\mathrm{pH}$ ACSF for at least $10 \mathrm{~min}$ until the intracellular recording of tonic firing neurons became stable. Then, the superfusate was changed to control ACSF $\left(2 \% \mathrm{CO}_{2}\right)$ for $8 \mathrm{~min}$ to assess $\mathrm{CO}_{2}$ sensitivity of tonic firing neurons. If the membrane potential of neurons was hyperpolarized by changing superfusate from high $\mathrm{CO}_{2}$ /low $\mathrm{pH}$ ACSF to control ACSF, we considered these neurons to be chemosensitive and continued the protocol. Then, the superfusate was changed to control ACSF (10 min). Next, high $\mathrm{CO}_{2}$ /low $\mathrm{pH}$ ACSF was changed to high $\mathrm{CO}_{2}$ /low $\mathrm{pH}$ ACSF containing D-TC $40 \mu \mathrm{M}$ or $\mathrm{VB} 40 \mu \mathrm{M}$ for $3-5$ min to analyze 
effects of NMBAs on chemosensitive neurons, followed by high $\mathrm{CO}_{2}$ /low $\mathrm{pH}$ ACSF (10 min). We examined the change of $\mathrm{E}_{\mathrm{m}}(\mathrm{mV})$ and firing frequency $(\mathrm{Hz})$ of tonic firing neurons. All parameters were measured for 2-3 minutes at the end of each period.

\section{Statistical Analyses}

The original peak values of $\mathrm{D} f_{\mathrm{R}}$ with and without NMBAs were analyzed by using a paired $t$-test. Effects on tonic firing neurons were analyzed with a paired $t$-test. All data were expressed as mean \pm SEM. $P$ value $<$ 0.05 was considered to be significant.

\section{RESULTS}

Effects of neuromuscular blocking agents on respiratory $\mathrm{CO}_{2}$ responsiveness

The superfusion of hypercapnic ACSF induced an increase in $f_{\mathrm{R}}$. This increase of $f_{\mathrm{R}}$, respiratory $\mathrm{CO}_{2}$ responsiveness, was suppressed by D-TC $10 \mu \mathrm{M}(\mathrm{p}<0.05$; Figure 1) and $100 \mu \mathrm{M}(\mathrm{p}<0.05)$, but not by D-TC 1 $\mu \mathrm{M}$ (Table I).

VB $10 \mu \mathrm{M}$ did not affect respiratory $\mathrm{CO}_{2}$ responsiveness, but $\mathrm{VB} 100 \mu \mathrm{M}$ suppressed respiratory $\mathrm{CO}_{2}$ responsiveness $(\mathrm{p}<0.01$; Table I). In 5 out of 26 preparations, VB $100 \mu \mathrm{M}$ induced $\mathrm{C} 4$ tonic discharge. These
C4 tonic discharges disappeared with an increase of the $\mathrm{CO}_{2}$ fraction from $2 \%$ to $8 \%$ in the superfusate (Figure 2).

After switching from control ACSF to ACSF containing D-TC $100 \mu \mathrm{M}$ or VB 100 $\mu \mathrm{M}$, respiratory activity was completely suppressed in 4 out of 19 preparations or 6 out of 26 preparations, respectively. In these 10 preparations, respiratory activities completely silenced by NMBAs were not restored by $8 \% \mathrm{CO}_{2}$. We excluded these preparations in which $\mathrm{VB}$ induced $\mathrm{C} 4$ tonic discharge or NMBAs induced complete disappearance of respiratory activities from the evaluation of respiratory $\mathrm{CO}_{2}$ responsiveness.

\section{Effects of neuromuscular blocking agents on chemosensitive neurons}

Tonic firing neurons were divided on the basis of their response of $\mathrm{E}_{\mathrm{m}}$ to the increase of $\mathrm{CO}_{2}$ fraction of the superfusate from $2 \%$ to $8 \%$ into three groups - excited (chemosensitive), inhibited and insensitive (Table 2). In the RVLM, three types of neurons were located, but we did not test the effects of NMBAs on $\mathrm{CO}_{2}$-inhibited and insensitive neurons in this study. In all of recorded $\mathrm{CO}_{2}$-excited neurons $(\mathrm{n}=5)$, DTC or VB induced hyperpolarization of $E_{m}$ $(\mathrm{p}<0.01, \mathrm{p}<0.05$ respectively) and decreases in firing frequency $(\mathrm{p}<0.05$ respectively; Figure 3; Table 3).

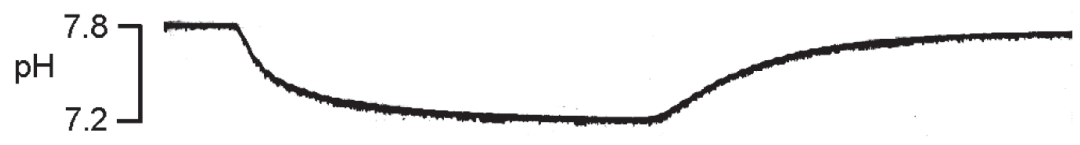

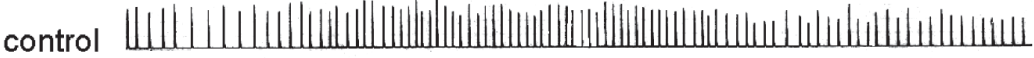

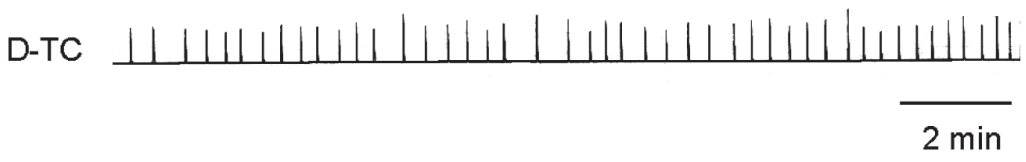

Figure 1. Effects of d-tubocurarine (D-TC) on respiratory $\mathrm{CO}_{2}$ responsiveness. Switching the superfusate from control ACSF $\left(\mathrm{CO}_{2} 2 \% ; \mathrm{pH}=7.8\right)$ to hypercapnic ACSF $\left(\mathrm{CO}_{2} 8 \% ; \mathrm{pH}=7.2\right)$ led to an increase of $f_{\mathrm{R}}$. The respiratory $\mathrm{CO}_{2}$ responsiveness was attenuated by D-TC $10 \mu \mathrm{M}$. The $\mathrm{pH}$ of the superfusate was continuously monitored, and is presented at the top of the figure. Bottom traces show integrated $\mathrm{C} 4$ activity. 
TABLE I

Effects of neuromuscular blocking agents (NMBAs) on respiratory $\mathrm{CO}_{2}$ responsiveness

\begin{tabular}{|c|c|c|c|c|c|c|c|c|}
\hline & & \multirow[b]{3}{*}{$\mathrm{n}$} & \multicolumn{3}{|c|}{ Before application of NMBAs } & \multicolumn{3}{|c|}{ During application of NMBAs } \\
\hline & & & \multicolumn{2}{|c|}{$f_{\mathrm{R}}\left(\min ^{-1}\right)$} & \multirow[t]{2}{*}{$\mathrm{D} f_{\mathrm{R}}\left(\mathrm{min}^{-1}\right)$} & \multicolumn{2}{|c|}{$f_{\mathrm{R}}\left(\min ^{-1}\right)$} & \multirow[t]{2}{*}{$\mathrm{D} f_{\mathrm{R}}\left(\mathrm{min}^{-1}\right)$} \\
\hline & & & $2 \% \mathrm{CO}_{2}$ & $8 \% \mathrm{CO}_{2}$ & & $2 \% \mathrm{CO}_{2}$ & $8 \% \mathrm{CO}_{2}$ & \\
\hline \multirow[t]{3}{*}{ d-tubocurarine } & $1 \mu \mathrm{M}$ & 7 & $5.2 \pm 1.0$ & $7.2 \pm 1.0$ & $1.9 \pm 0.6$ & $5.3 \pm 0.7$ & $7.7 \pm 1.1$ & $2.4 \pm 0.9$ \\
\hline & $10 \mu \mathrm{M}$ & 10 & $5.3 \pm 0.5$ & $6.9 \pm 0.4$ & $1.6 \pm 0.2$ & $4.3 \pm 0.8$ & $5.0 \pm 0.8$ & $0.8 \pm 0.4 *$ \\
\hline & $100 \mu \mathrm{M}$ & 15 & $6.3 \pm 0.6$ & $8.7 \pm 0.6$ & $2.4 \pm 0.4$ & $5.4 \pm 0.6$ & $6.6 \pm 0.5$ & $1.3 \pm 0.5^{*}$ \\
\hline \multirow{2}{*}{$\begin{array}{l}\text { vecuronium } \\
\text { bromide }\end{array}$} & $10 \mu \mathrm{M}$ & 15 & $4.1 \pm 0.5$ & $6.6 \pm 0.5$ & $2.5 \pm 0.5$ & $3.7 \pm 0.4$ & $5.9 \pm 0.5$ & $2.3 \pm 0.4$ \\
\hline & $100 \mu \mathrm{M}$ & 15 & $4.2 \pm 0.7$ & $6.5 \pm 0.7$ & $2.3 \pm 0.3$ & $4.0 \pm 0.6$ & $4.8 \pm 0.6$ & $0.8 \pm 0.3 * *$ \\
\hline
\end{tabular}

Data are presented as mean \pm SEM.

$* \mathrm{p}<0.05$

$* * \mathrm{p}<0.01$

$2 \% \mathrm{CO}_{2}(\mathrm{VB}) \quad 8 \% \mathrm{CO}_{2}(\mathrm{VB})$

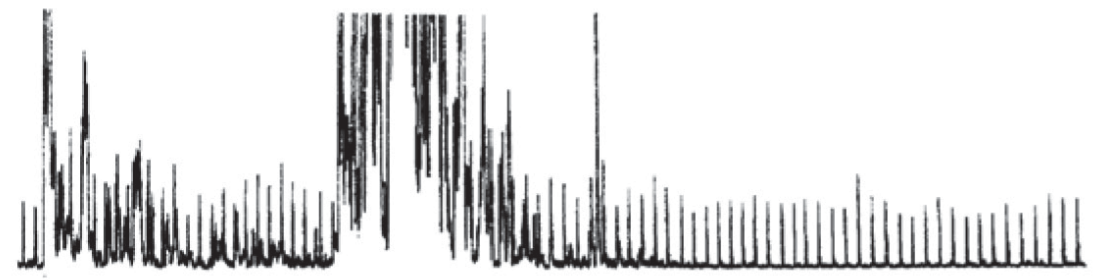

\section{$2 \min$}

Figure 2. Representative $C 4$ tonic discharge induced by high concentration of vecuronium bromide $(V B)$ and its restoration by hypercapnia. High concentration of VB $(100 \mu \mathrm{M})$ induced $\mathrm{C} 4$ tonic discharge at low $\mathrm{CO}_{2}(2 \%)$ superfusate in 5 out of 26 preparations. However, these $\mathrm{C} 4$ tonic discharges disappeared, and normal regular respiratory $\mathrm{C} 4$ activity was restored by elevating $\mathrm{CO}_{2}$ fraction of the superfusate to $8 \%$ in all 5 preparations. Trace shows integrated C4 activity.

TABLE II

Characteristics of tonic firing neurons in the rostral ventrolateral medulla

\begin{tabular}{|c|c|c|c|c|c|}
\hline & \multirow[b]{2}{*}{$\mathrm{n}$} & \multicolumn{2}{|c|}{$E_{m}(m V)$} & \multicolumn{2}{|c|}{ Firing frequency $(\mathrm{Hz})$} \\
\hline & & $2 \% \mathrm{CO}_{2}$ & $8 \% \mathrm{CO}_{2}$ & $2 \% \mathrm{CO}_{2}$ & $8 \% \mathrm{CO}_{2}$ \\
\hline $\mathrm{CO}_{2}$-insensitive & 3 & $-51.1 \pm 8.1$ & $-51.1 \pm 8.1$ & $0.44 \pm 0.43$ & $0.47 \pm 0.46$ \\
\hline $\mathrm{CO}_{2}$-depressed & 1 & -55 & -62 & 0.3 & 0.3 \\
\hline $\mathrm{CO}_{2}$-excited & 5 & $-50.6 \pm 3.6$ & $-47.7 \pm 3.7$ & $0.49 \pm 0.19$ & $1.0 \pm 0.45$ \\
\hline
\end{tabular}

Data are presented as mean \pm SEM. 


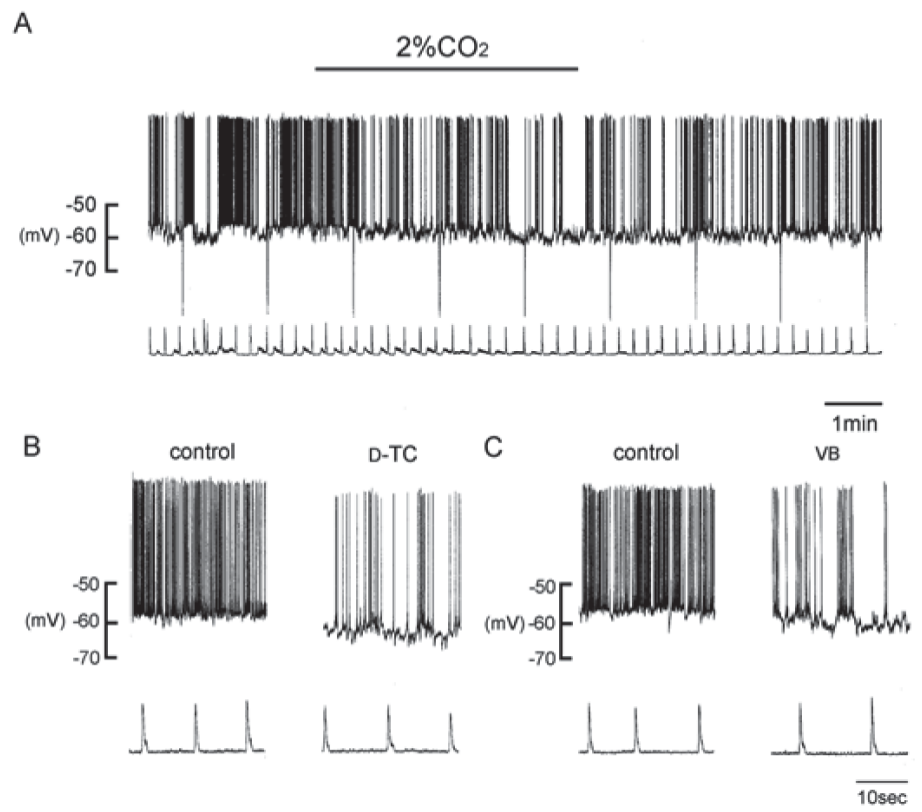

Figure 3. Effects of neuromuscular blocking agents on chemosensitive neurons. Representative activity of $\mathrm{CO}_{2}$-excited neuron (A) and the effects of d-tubocurarine (D-TC) $40 \mu \mathrm{M}$ (B) and vecuronium bromide (VB) $40 \mu \mathrm{M}(\mathrm{C})$ on this chemosensitive neuron. Top traces of each figure show the membrane potential of $\mathrm{CO}_{2}$-excited neuron. In this recording, $-5 \mathrm{nA}$ current pulse (300 ms duration) was applied every 20 seconds for measurement of input resistance. Bottom traces of each figure show integrated $\mathrm{C} 4$ activity.

TABLE III

Effects of neuromuscular blocking agents (NMBAs) on chemosensitive non-respiratory-excited neurons

\begin{tabular}{lccccc}
\hline & \multicolumn{2}{c}{ Before application of NMBAs } & & \multicolumn{2}{c}{ During application of NMBAs } \\
\cline { 6 - 6 } \cline { 5 - 6 } & $\mathrm{E}_{\mathrm{m}}(\mathrm{mV})$ & Firing frequency $(\mathrm{Hz})$ & & $\mathrm{E}_{\mathrm{m}}(\mathrm{mV})$ & Firing frequency $(\mathrm{Hz})$ \\
\hline d-tubocurarine & $-48.6 \pm 3.0$ & $0.7 \pm 0.3$ & & $-50.1 \pm 3.1^{* *}$ & $0.5 \pm 0.2^{*}$ \\
vecuronium bromide & $-48.9 \pm 3.1$ & $0.6 \pm 0.4$ & & $-49.7 \pm 2.9^{*}$ & $0.5 \pm 0.3^{*}$ \\
\hline
\end{tabular}

Data are presented as mean \pm SEM.

$* \mathrm{p}<0.05$

$* * \mathrm{p}<0.01$

\section{DISCUSSION}

In the present study, we have shown that the sole application of d-tubocurarine and vecuronium attenuates respiratory $\mathrm{CO}_{2}$ responsiveness in an isolated brainstemspinal cord preparation of the neonatal rat. Also, these agents induce hyperpolarization of $E_{m}$ and decreases in firing frequency of $\mathrm{CO}_{2}$-excited neurons in the RVLM. These results suppose that NMBAs suppress respiratory $\mathrm{CO}_{2}$ responsiveness at least partly by inhibiting the activity of $\mathrm{CO}_{2}$ excited neurons in the RVLM.

Respiratory $\mathrm{CO}_{2}$ responsiveness in the isolated brainstem-spinal cord preparation of neonatal rat

In contrast to in vivo studies where hypercapnia causes an increase in tidal volume (Loeschcke, 1982; Millhorn \& 
Eldridge, 1986; Bruce \& Cherniack, 1987), it is controversial how hypercapnia induces changes in $\mathrm{C} 4$ activities in the isolated brainstem-spinal cord preparation of neonatal rat. Most studies indicate that hypercapnia induces increases in respiratory frequency (Suzue, 1984; Issa \& Remmers, 1992; Okada et al., 1993b; Kawai et al., 1996; Voipio \& Ballanyi, 1997; Kuwana et al., 2000a), although some studies have shown that it induces increases in $\mathrm{C} 4$ amplitude (Monteau et al., 1990) or both (Harada et al., 1985). It is also controversial whether central chemosensitivity of respiratory control depends on $\mathrm{pH}$ (Suzue, 1984; Harada et al., 1985) or $\mathrm{CO}_{2}$ (Harada et al., 1985). Therefore, we evaluated respiratory $\mathrm{CO}_{2}$ responsiveness as the difference of $f_{\mathrm{R}}$ between $2 \% \mathrm{CO}_{2}(\mathrm{pH}=7.8)$ and $8 \% \mathrm{CO}_{2}(\mathrm{pH}=7.2)$ in the present study.

\section{Chemosensitivity and cholinergic mechanism}

Chemosensitive tonic firing neurons are present in the ventral surface of medulla in rat (Fukuda \& Loeschcke, 1979; Fukuda, 1983; Jarolimek et al., 1990; Richerson, 1995; Okada et al., 2002) and in the isolated brainstem-spinal cord of neonatal rat (Okada et al., 1993b; Kawai et al., 1996; Kuwana et al., 1998). Several previous studies have shown that cholinergic mechanism is involved in the central chemoreception. (Fukuda \& Loeschcke, 1979; for review, see Nattie, 1999, Okada et al., 2001). Fukuda and Loeschcke (1979) showed that these chemosensitive neurons excited by $\mathrm{H}^{+}$are excited by $\mathrm{ACh}$ and the cholinesterase inhibitor eserine. Furthermore, these $\mathrm{H}^{+}-$ elicited excitation are blocked by muscarinic Ach-receptor antagonist atropine and the nAChR antagonist hexamethonium and mecamylamine in the medulla slice preparation of rats. Furthermore, Dermietzel and colleagues (1983) showed the existence of nAChRs in the chemosensitive area of the rat ventral medulla by the acetylcholinesterase staining-technique. Hence, cholinergic mechanisms seem to be involved in central chemosensitivity.

It has been shown that chemostimulation induces increases in tonic firing frequency
(Fukuda \& Loeschcke, 1979; Fukuda, 1983; Jarolimek et al., 1990; Okada et al., 1993b; Richerson, 1995; Kuwana et al., 1998; Okada et al., 2002) or induces depolarization of most chemosensitive neurons in the RVLM (Kawai et al., 1996; Kuwana et al., 1998). In the present study, D-TC and VB induced hyperpolarization of $\mathrm{E}_{\mathrm{m}}$ and decreased firing frequency of $\mathrm{CO}_{2}$-excited neurons. Our result thus supposes that $\mathrm{nAChRs}$ are involved in $\mathrm{CO}_{2}$ excitation of central respiratory neuronal network. However, we also have to take into account the possibility of neuronal nAChRs in motoneurons, because it has been indicated that neuronal $\mathrm{nAChR}$ is also included in motoneurons (Chamberlin et al., 2002; Wang et al., 2002), and it is blocked by D-TC in the slice preparation of the neonatal rats (Wang et al., 2002).

\section{Connection between chemosensitive area} and central respiratory control

It is assumed that the tonic firing of these chemosensitive neurons in the RVLM induce an excitatory drive to the neuronal network that generates the respiratory rhythm (Eugenin \& Nicholls, 1997; Richerson, 1998; for review, see Eugenin et al., 2001). Indeed, the local application of carbachol to $\mathrm{H}^{+}$- and cholinergic-sensitive area in the RVLM induces a change of respiratory pattern similarly to low $\mathrm{pH}$ application, and these enhancements of respiration are diminished by muscarinic Ach-receptor antagonist scopolamine in the isolated brainstem-spinal cord of neonatal opossum (Eugenin \& Nicholls, 1997). This study indicates that cholinergic mechanisms and chemosensitive $\mathrm{CO}_{2}$-excited neurons in the RVLM possess the same pathway to respiratory activity. Furthermore, respiratory $\mathrm{CO}_{2}$ responsiveness is partly inhibited by the non-selective nAChR antagonist mecamylamine and the a4b2 nAChR selective antagonist dihydro-berythroidine in the isolated brainstem-spinal cord preparation of neonatal rat (Kuwana et al., 2000a,b). Our previous study has revealed that two NMBAs (D-TC and VB) attenuate central respiratory control in the isolated brainstem-spinal cord of neonatal rat (Sakuraba et al., 2003). This occurs when these two NMBAs are used, irrespective of 
their different molecular structure (esterbased versus aminosteroid-based) and possible different affinity for neuronal nAChR. We therefore speculate that NMBAs in general inhibit chemosensitive neurons, which send an excitatory drive to respiratory rhythm generating network, via a 4 b2 $\mathrm{nAChR}$, and hereby attenuate respiratory $\mathrm{CO}_{2}$ responsiveness, even if the direct relationship between $\mathrm{nAChR}$ of chemosensitive areas and respiratory activity have not been investigated. Further studies are now needed to elucidate this direct relationship and what subunits of $\mathrm{nAChR}$ are affected by NMBAs.

\section{Intrinsic chemosensitivity of preinspiratory neurons and neuromuscular blocking agents}

It has shown that preinspiratory neurons, respiratory rhythm generator, in the RVLM have intrinsic $\mathrm{pH}$ sensitivities in the blockade of synaptic transmission (Onimaru et al., 1989; Ballanyi et al., 1999). Also, our previous study has shown that D-TC and VB suppress the central respiratory control partly by their inhibitory effects on preinspiratory neurons (Sakuraba et al., 2003). Taken together, D-TC and VB attenuated respiratory $\mathrm{CO}_{2}$ responsiveness partly due to their inhibitory effects on the intrinsic chemosensitivities of preinspiratory neurons. However, this study provides no information as to whether the attenuation of respiratory $\mathrm{CO}_{2}$ responsiveness is only dependent on the inhibitory effects on chemosensitive $\mathrm{CO}_{2}$-excited neurons. Further studies are needed to clarify whether NMBAs inhibit intrinsic $\mathrm{pH}$ sensitivities of preinspiratory neurons and thus attenuate respiratory $\mathrm{CO}_{2}$ responsiveness.

\section{C4 tonic discharge}

In the present study, high concentration of $\mathrm{VB}$ induces $\mathrm{C} 4$ tonic discharge and these activities disappeared when the $\mathrm{CO}_{2}$ fraction in the superfusate was increased from $2 \%$ to $8 \%$. It is consistent with our previous studies that high concentration of VB induces $\mathrm{C} 4$ tonic discharge due to the action of VB on the spinal cord, not on medulla (Sakuraba et al., 2003), and that high concentration of calcium in the superfusate induces $\mathrm{C} 4$ tonic discharge even after most of medulla is ablated, and it is restored by elevating $\mathrm{CO}_{2}$ fraction in the superfusate (Kuwana et al., 1998).

The exact mechanism underlying VBinduced $\mathrm{C} 4$ tonic discharge and their restoration with elevated $\mathrm{CO}_{2}$ is not known. Intracerebral administration of $\mathrm{VB}$ into the CNS evokes acute excitation, shivering and myotonic contractions due to motoneuron excitation in rats (Szenohradszky et al., 1993). This may be caused by accumulation of cytosolic calcium due to VB-induced sustained activation of neuronal nAChRs with subsequent increase in calcium influx through calcium channels (Vernino et al., 1992; Cardone et al., 1994). Also, the restorative effect of $\mathrm{CO}_{2}$ on VB-induced $\mathrm{C} 4$ tonic discharge may be explained as inhibition of calcium channels by hydrogen ions (Krafte \& Kass, 1988; Takahashi et al., 1993).

In conclusion, the neuromuscular blocking agents, d-tubocurarine and vecuronium, attenuate respiratory $\mathrm{CO}_{2}$ responsiveness partly by their inhibitory effects on chemosensitive neurons in the RVLM.

\section{ACKNOWLEDGEMENTS}

This work was supported in part by the Keio Gijuku Postgraduate School Fund for the Advancement of Research (S.S.), the Keio University Grant-in-Aid for Encouragement of Young Medical Scientists (S.S.), the Scandinavia-Japan Sasakawa Foundation (S.S.), and the Smoking Research Foundation (S.K.), and the Grant-in-Aid for Scientific Research from the Japanese Ministry of Education, Science and Culture (J.T.).

\section{REFERENCES}

BALLANYI K, ONIMARU H, HOMMA I (1999) Respiratory network function in the isolated brainstemspinal cord of newborn rats. Prog Neurobiol 59: 583-634

BRUCE EN, CHERNIACK NS (1987) Central chemoreceptors. J Appl Physiol 62: 389-402

CARDONE C, SZENOHRADSZKY J, YOST S, BICKLER PE (1994) Activation of brain acetylcholine receptors by neuromuscular blocking drugs. Anesthesiology 80: $1155-1161$ 
CHAMBERLIN NL, BOCCHIARO CM, GREENE RW, FELDMAN JL (2002) Nicotinic excitation of rat hypoglossal motoneurons. Neuroscience 115: 861-870

CHIODINI F, CHARPANTIER E, MULLER D, TESSONYI E, FUCHS-BUDER T, BERTRAND D (2001) Blockade and activation of the human neuronal nicotinic acetylcholine receptors by atracurium and laudanosine. Anesthesiology 94: 643-651

DEV NB, LOESCHCKE HH (1979) A cholinergic mechanism involved in the respiratory chemosensitivity of the medulla oblongata in the cat. Pflügers Archiv 379: 29-36

DERMIETZEL R, WILLENBERG I, LEIBSTEIN A (1983) Histochemical studies on the central chemosensitive fields of the medulla oblongata. In: SCHLAFKE ME, KOEPCHEN HP, SEE WR (eds) Central Neurone Environment and the Control Systems of Breathing and Circulation. Berlin: Springer Verlag. pp: 251-256

EUGENIN J, NICHOLLS JG (1997) Chemosensory and cholinergic stimulation of fictive respiration in isolated CNS of neonatal opossum. J Physiol, London 501: 425437

EUGENIN J, LLONA I, INFANTE CD, AMPUERO E (2001) In vitro approach to the chemical drive of breathing. Biol Res 34: 117-122

FUKUDA Y, LOESCHCKE HH (1979) A cholinergic mechanism involved in the neuronal excitation by $\mathrm{H}^{+}$ in the respiratory chemosensitive structures of the ventral medulla oblongata of rats in vitro. Pflügers Archiv 379: 125-135

FUKUDA Y (1983) Difference between actions of high $\mathrm{P}_{\mathrm{CO} 2}$ and low [ $\mathrm{HCO}^{-}$] on neurons in the rat medullary chemosensitive areas in vitro. Pflügers Archiv 398: 324-330

HARADA Y, KUNO Y, WANG YZ (1985) Differential effects of carbon dioxide and $\mathrm{pH}$ on central chemoreceptors in the rat in vitro. J Physiol, London 369: 679-693

ISSA FG, REMMERS JE (1992) Identification of a subsurface area in the ventral medulla sensitive to local changes in $\mathrm{P}_{\mathrm{CO} 2}$. J Appl Physiol 72: 439-446

JAROLIMEK W, MISGELD U, LUX HD (1990) Neurons sensitive to $\mathrm{pH}$ in slices of the rat ventral medulla oblongata. Pflügers Archiv 416: 247-253

KAWAI A, BALLANTYNE K, MÜCKENHOFF K, SCHEID P (1996) Chemosensitive medullary neurones in the brainstem-spinal cord preparation of the neonatal rat. J Physiol, London 492: 277-292

KRAFTE DS, KASS RS (1988) Hydrogen ion modulation of $\mathrm{Ca}$ channel current in cardiac ventricular cells. J Gen Physiol 91: 641-657

KUWANA S, OKADA Y, NATSUI T (1998) Effects of extracellular calcium and magnesium on central respiratory control in the brainstem-spinal cord of neonatal rat. Brain Res 786: 194-204

KUWANA S, OKADA Y, IWANAMI M (2000a) Effects of nicotinic $\mathrm{ACh}$ receptor antagonists on central respiratory chemosensitivity in the neonatal rat. Neurosci Res 24 (Suppl): S172

KUWANA S, OKADA Y, IWANAMI M, NATSUI T (2000b) Effects of nicotine and nicotinic receptor antagonist on central respiratory control in the isolated brain stem-spinal cord of neonatal rat. Jpn J Physiol 50 (Suppl): S82

LINDSTROM J, ANAND R, PENG X, GERZANICH V, WANG F, LI Y (1995) Neuronal nicotinic receptor subtypes. Ann NY Acad Sci 757: 100-116
LOESCHCKE HH (1982) Central chemosensitivity and the reaction theory. J Physiol, London 332: 1-24

MILLHORN DE, ELDRIDGE FL (1986) Role of ventrolateral medulla in regulation of respiratory and cardiovascular systems. J Appl Physiol 61: 1249-1263

MONTEAU R, MORIN D, HILAIRE G (1990) Acetylcholine and central chemosensitivity: In vitro study in the newborn rat. Respir Physiol 81: 241-254

NATTIE E (1999) $\mathrm{CO}_{2}$, brainstem chemoreceptors and breathing. Prog Neurobiol 59: 299-331

OKADA Y, MÜCKENHOFF K, HOLTERMANN G, ACKER H, SCHEID P (1993a) Depth profiles of $\mathrm{pH}$ and $\mathrm{PO}_{2}$ in the isolated brain stem-spinal cord of the neonatal rat. Respir Physiol 93: 315-326

OKADA Y, MÜCKENHOFF K, SCHEID P (1993b) Hypercapnia and medullary neurons in the isolated brain stem-spinal cord of the rat. Respir Physiol 93: 327-336

OKADA Y, CHEN Z, KUWANA S (2001) Cytoarchitecture of central chemoreceptors in the mammalian ventral medulla. Respir Physiol 129: 13-23

OKADA Y, CHEN Z, JIANG W, KUWANA S, ELDRIDGE FL (2002) Anatomical arrangement of hypercapnia-activated cells in the superficial ventral medulla of rats. J Appl Physiol 93: 427-439

ONIMARU H, ARATA A, HOMMA I (1989) Firing properties of respiratory rhythm generating neurons in the absence of synaptic transmission in rat medulla in vitro. Exp Brain Res 76: 530-536

RICHERSON GB (1995) Response to $\mathrm{CO}_{2}$ of neurons in the rostral ventral medulla in vitro. J Neurophysiol 73: 933-944

RICHERSON GB (1998) Cellular mechanisms of sensitivity to $\mathrm{pH}$ in the mammalian respiratory system. In: KAILA K, RANSOM BR (eds) $\mathrm{pH}$ and Brain Function. New York: Wiley-Liss. pp: 503-593

SAKURABA S, KUWANA S, OCHIAI R, OKADA Y, KASHIWAGI M, HATORI E, TAKEDA J (2003) Effects of neuromuscular blocking agents on central respiratory control in the isolated brainstem-spinal cord of neonatal rat. Neurosci Res 47: 289-298

SUZUE T (1984) Respiratory rhythm generation in the in vitro brain stem-spinal cord preparation of the neonatal rat. J Physiol, London 354: 173-183

SZENOHRADSZKY J, TREVOR A, BICKLER P, CALDWELL J, SHARMA M, RAMPIL I, MILLER RD (1993) Central nervous system effects of intrathecal muscle relaxants in awake rats. Anesth Analg 76: 1304-1309

TAKAHASHI K, DIXON DB, COPENHAGEN DR (1993) Modulation of a sustained calcium current by intracellular $\mathrm{pH}$ in horizontal cells of fish retina. J Gen Physiol 101: 695-714

VERNINO S, AMADOR M, LUETJE CW, PATRICK J, DANI JA (1992) Calcium modulation and high calcium permeability of neuronal nicotinic acetylcholine receptors. Neuron 8: 127-134

VOIPIO J, BALLANYI K (1997) Interstitial $\mathrm{P}_{\mathrm{CO} 2}$ and $\mathrm{pH}$ and their role as chemostimulants in the isolated respiratory network of neonatal rats. J Physiol, London 499: 527-542

WANG J, IRNATEN M, VENKATESAN P, EVANS C, BAXI S, MENDELOWITZ D (2002) Synaptic activation of hypoglossal respiratory motorneurons during inspiration in rats. Neurosci Lett 332: 195-199. 